\title{
Pedro Gil: teacher, researcher, mentor, leader and colleague at the University of Oviedo
}

\author{
Norberto Corral and Manuel Montenegro
}

As it has been already mentioned by Infante Macías, Pedro Gil joined the Department of Statistics and OR in 1969 as a research and teaching assistant. Partially thanks to a fellowship from Fundación Juan March, he completed his PhD Dissertation in 1974, under the supervision of Professor Sixto Ríos, at the Complutense University of Madrid (see [2] for a published version of this PhD thesis). Professor Ríos was a doctoral student of Professor Julio Rey Pastor (see Part 1 of this book), and he is considered to be the main driver and promoter of Statistics and OR in Spain.

After getting the PhD Degree in Mathematics, Pedro Gil continued working on researching and teaching with the ultimate goal of applying at any appropriate moment for a tenure-track position at the university. This opportunity arose possibly earlier than expected, and it concerned a position in between Associate and Full professorship (coined as Profesor Agregado, a position that was extinguished many years ago). To directly apply to this high level permanent position was not certainly the typical and easiest path into an academic career in the field. Nevertheless, when Pedro was twentyeight years old he became Profesor Agregado in Operations Research of the University of Oviedo.

In 1976, a twenty-eight years old Pedro Gil moved along with his young family (at that moment composed of his wife, Pilar, his eldest daughter, Eva, and himself) from Madrid to Oviedo. This was the embryo of a family who has been the main engine of his life, and that was completing with two other children, Juan and Eduardo and, much later, with their grandchildren.

Moving from Madrid meant, on one hand, abandoning the 'scientific nest' that had been created around Professor Ríos by many endearing colleagues and friends. Anyway, he had always kept in touch with them, and the periodic Conferences of the Spanish Society of Statistics and OR (SEIO) were the perfect excuse not to lose that strong relationship.

Departamento de Estadística, I.O. y D.M., Universidad de Oviedo, Spain, \{norbert, mmontenegro\}@uniovi.es 
On the other hand, moving from Madrid entailed too many responsibilities for a young professional. In the University of Oviedo he was affiliated to the Faculty of Sciences, where the presence of mathematicians had been very scarce and was very longed for. So, he was quite enthusiastically welcome. But, from the very beginning, he was aware about him having to assume a leadership position in all possible respects related to the Department of Mathematics of the Faculty of Sciences, namely:

- heading the Department, what means being involved in the management of many bureaucracies and commitments;

- recruiting people (a complex task in a university not having the BSc Degree in Mathematics at that moment, see the paper by Dugnol and Valdés, just after this one in the book);

- guiding the teaching of the recruited people, since the first ones were young mathematicians (most of them with only a BSc degree);

- supervising the research of the recruited people;

And Pedro wanted this to be made in the most rigorous way possible. And, in spite of his (starting) youth, he got it. And he became an excellent teacher, a good and generous researcher and mentor, a sympathetic boss, and deeply beloved by all of his colleagues. Let us now briefly detail each of these facets.

\section{Pedro as teacher}

When Pedro arrived to Oviedo he had the expertise of having delivered courses on many different Statistics and OR disciplines. Actually, this expertise was crucial in both, guiding and helping the young collaborators he was recruiting in their teaching endeavors, and coordinating the launching and design of the BSc in Mathematics for the University of Oviedo (as it will be later explained in more depth by Dugnol and Valdés).

In 1976, the Mathematics Department Pedro headed had to be in charge of General Mathematics (mainly involving Calculus and Algebra) and Statistics for Biology, Chemistry, Geology and also Statistics/OR for Economics. And he taught some of the courses, especially those concerning Statistics, being the first mathematician teaching some of them in Oviedo.

Although the students might initially be suspicious of the increase in rigor and proficiency level that surely occurred at that time, they soon realized that such an increase was accompanied by clear explanations, well-argued motivations and a strong empathy to students. Even those being highly averse to Mathematics admitted Pedro's teaching excellence.

Of course, this opinion was increasing in the nineties of the last century, as the BSc in Math was launched in the University of Oviedo, and Pedro was teaching again to Math students (those for whom the aversion to Mathematics is assumed to be discarded). He had a strong background and knowledge, and he was especially skilled at transmitting them. In fact, most of students 
confess that because of the clarity of their explanations, they believed that the courses were simpler than they were.

Furthermore, Pedro was always ready to listen to the students, advice them, solve their doubts, answer their questions, and so on. Most of these questions were mathematical, but they also concerned their future working lives, and even some rather personal matters.

At the end of the first quarter, just before Christmas, students of the BSc in Mathematics organized a special event in which they (often with some professors) sang, made gymkanas and other competitions, parodies, etc. And a permanent participant in all of these events was Pedro. With his accordion, he played a well-known Basque song 'El Alcalde de Arrigorriaga', after writing the lyrics on the blackboard and indicating students the movements of going up and down alternately in the chorus ("Pantalen, Pantalen, ...."). If possible, this made him even closer to the students.

Pedro's warm attitude supported the frequent (informal albeit affectionate) nicknames students used in referring to him: Father Pedro or even Saint Pedro.

\section{Pedro as researcher and mentor}

From the very beginning of his scientific career, Pedro was firmly convinced of the importance of research in academic life. And he tried to convey to his $\mathrm{PhD}$ students and people at his Department this conviction. He tried also to show the benefits of the synergies between research and teaching.

He was the main example for us in this respect. Actually, he got the maximum possible number of research activity evaluation six-year periods in Spain, the so-called 'sexenios de investigación'. And his expertise made much easier our first approach to research.

Research was probably the most visible and best test of Pedro's generosity. He tried to ensure the highest levels of rigour and quality in all research undertaken under his supervision, as well as to create a dynamic and ethic atmosphere around. Since he does not believe in hierarchical structures, he encouraged us to become gradually independent in research tasks (either in writing papers, in applying for granted research projects, etc.) This policy based on gradual independence, evolution and generational change has certainly led to an enrichment of the research activities and directions in the Department.

Despite his many duties in heading first Mathematics Department of the former Faculty of Sciences and later the Statistics, OR and Teaching Math Department of the University of Oviedo, Pedro was permanently involved in research tasks. He supervised $20 \mathrm{PhD}$ Thesis. His first supervision started at the Complutense University of Madrid, the PhD Student being M. Pilar García-Carrasco. The Dissertation was completed in 1978 and dealt with the 
comparison of statistical experiments (see [1] as well as comments made about by de la Horra in the preceding paper in this book).

Pedro supervised other $19 \mathrm{PhD}$ theses in the University of Oviedo. He fervently defended that the $\mathrm{PhD}$ Thesis should be a high level research work. But it should not be our highest level research. We should scientifically grow and do better jobs every time. As mentor, Pedro guaranteed support, guidance, encouragement and understanding at every stage.

\section{Pedro as leader and colleague}

Since Pedro arrived at Oviedo, he had to act as a leader and manager. Everyone noticed his high ability to hold management positions, and he realized that for a newly created Department at the University, it was advisable the head was involved in many management aspects. Moreover, he was also aware on his skills and fondness for the scientific research. So, with much effort and personal work he had to combine both leaderships. Before being thirty years old he was holding, among others, the Directions of the Mathematics Department at the Faculty of Sciences, the Academic Secretary for such a Faculty, and the supervision of four doctoral theses. We must admit that we have not yet been able to discover how he could do so in the right way in which he did it.

Some years later he was holding several other positions, supervising many other doctoral theses and research works, and heading the first research projects conducted in the Department. But, in view of the principles, this is not surprising at all. Among the positions he held, to be three-years President of the Spanish Society of Statistics and OR, SEIO, was quite grateful. Pedro and his wife were unconditional participants in all SEIO's Conferences.

After some educational changes in Spain, that are detailed in the next paper by Dugnol and Valdés in this book, in 1997 a new department was created in the University of Oviedo: the Department of Statistics, Operations Research and Teaching Mathematics. Since its creation, Pedro was the head (and indisputable soul) of this Department. And, much to his regret, he did not get anyone to relieve him until his retirement in 2010. We all felt safe and sound under his warm protection.

Pedro was also our colleague and friend, and we we all knew he was there for any problems we could have. Nevertheless, we were not able to look at him exactly as one of us. In spite of some of us being only a few years younger than him, he had been taking care of us since the beginning, he was our boss, our supervisor, our scientific ancestor, and our personal support along the years in the University of Oviedo. So, for sure he was not one of us. He meant the creator, promoter, germ and heart of the project that began in 1976. 
In this respect, the homage held in the Paraninfo of the University of Oviedo to tribute him on the occasion of his retirement in 2010 (see https://youtu.be/APP4j5azLwo for the whole ceremony, in Spanish), was a parade of affection, admiration and recognition. Even an ad hoc choir, called 'Pantaleón', was set up for the special occasion, the eigth singers being either alumni, or scientific descendants, or colleagues or relatives, and the songs sung were some of his favorites in different times of his life.

\section{Pedro and the Mathematics in the University of Oviedo and in the Principality of Asturias}

As we have already mentioned, Pedro arrived to Asturias in 1976, when he was 28 years old. His tenure track position as 'Profesor Agregado' of the University of Oviedo was a necessary stage to get the Full Professorship. At that moment, after one to four years Agregados become Full Professors through an exposure of merits.

Maybe because of not having yet Mathematics BSc studies, the University of Oviedo delayed sightly more than four years in convening the position of Full Professor in Statistics. Meanwhile, the University of Santiago de Compostela offered the same position, and Pedro could apply to it under quite favorable conditions. It would be a nice opportunity in many professional and personal respects, namely: the University of Santiago had studies in Mathematics, with a long reputed tradition; he knew several members in Statistics and OR of this university, thanks to his friend Professor Ramiro Melendreras; his wife was born in la Puebla del Caramiñal (around $50 \mathrm{~km}$ far from Santiago), and joining Santiago University would mean approaching their family.

In this contingency, the members of his Department in Oviedo feared that their very young academic lives would undergo a major change by losing Pedro's leadership and protection. As a result of Pedro and his wife's generousity along with their love to Asturias, they decided not to move. We never thanked them as they deserved.

And his influence in the University of Oviedo and the advancement of Mathematics in the Principality of Asturias is beyond question.

As a proof of this assertion we can mention two outstandings achievements related to the University of Oviedo:

- At present, in the Department of Statistics, OR and Mathematics Teaching at the University of Oviedo there are 24 Pedro's 'scientific linear descendants', the distribution of this descendants being summarized in Table 1.

Furthermore, six PhD students of Pedro hold tenured positions in other departments of the University of Oviedo. 
Table 1 Distribution of Pedro's 'scientific linear descent' in the Department of Statistics, OR and Math Teaching at the University of Oviedo

\begin{tabular}{||c||c|c|c||}
\hline \hline $\begin{array}{c}\text { line of } \\
\text { 'scientific descent' }\end{array}$ & $\begin{array}{c}\text { Pedro's } \\
\text { child }\end{array}$ & $\begin{array}{c}\text { Pedro's } \\
\text { grandchild }\end{array}$ & $\begin{array}{c}\text { Pedro's } \\
\text { great-grandchild }\end{array}$ \\
\hline absolute freq. & 11 & 12 & 1 \\
\hline \hline
\end{tabular}

- As it will be commented to a certain extent in the next paper by Dugnol and Valdés, Pedro's expertise, knowledge and his permanent relationships with experts from other universities, were definitely crucial in the launching of the BSc in Mathematics in the University of Oviedo, as well as in the technical and academical elaboration and management of the starting BSc Programmes, in which one of the two considered specialties (which were oriented to the Principality of Asturias main demands) was Statistics (and OR). Probably, this was an idea hovering his mind since he arrived in Asturias. And Professor Benjamín Dugnol motivated him to do it by arguing that this will make possible having $\mathrm{PhD}$ in Mathematical Sciences by the University of Oviedo (something that prevented the laws in force at that time). And Professor Javier Valdés collaborated with him in this complex but exciting mission that, fortunately, succeeded.

Pedro did much for Math in Asturias, but not only for those at the university level. He always fostered cooperation between university education and previous education in Mathematics. As a proof of Pedro's influence of the Mathematics in the Principality of Asturias in connection with such a cooperation, let us refer to a few additional achievements:

- Since he arrived to Oviedo and for many years he coordinated Mathematics studies and examinations leading to university access. He visited many high schools, and called for many meetings with Math teachers, in order to explain what should be considered for students to know and handle as well as the basis for access exams. Readers should realize that Internet was not yet in our lives at that moment, so there is no chance for disseminating this key information but visits and meetings. Pedro believed in the need to make students and teacher more familiar with this information, and he added this new 'backpack' to the ones he already carried behind him.

- Also from the very beginning of his stay in Asturias till his retirement, Pedro was in charge of coordinating and organizing the Asturian Mathematical Olympiad for students of the one-two years before accessing the university. This was a national (as a second intermediate step between regional and international) competition seeking to improve Math education and creating greater interest in Mathematics careers among students. one more backpack on Pedro's shoulders.

- And, much more recently, and once he is retired, he has always participated in the scientific committees to select Asturian representatives for the Spanish Contest 'Incubator for Surveys and Experiments' sponsored by 
SEIO. A way to enhance the relevance of Statistics and OR in high school students, and making them more familiar with their techniques and tools by applying them to analyze data from different real-life problems.

When Pedro passed away in March 16, 2016, a headline of the newspaper 'La Nueva España' said that "Statistics become orphaned in Asturias". Well, we feel in this way to a great extent but, at the same time, you have left us many scientific and personal reserves that will always remain with us. Thank you, Pedro, for your care, your affection, your support, your modesty... in summary for you being as you were.

\section{References}

1. García-Carrasco Aponte MP (1978) Criterios para la comparacion de experimentos. Trab Estadíst Invest Oper 29(2):28-51 (https://link.springer.com/article/ 10.1007/BF02888673)

2. Gil P (1975) Medidas de incertidumbre e información en problemas de decisión estadística. Rev Real Acad Cienc Exact Fis Natur Madrid LXIX:549-610 (http://www.rac.es/ficheros/Revistas/REV_20091030_00137.pdf) 